\title{
Б.А. КАЛОЕВ КАК НАРТОВЕД
}

\section{Л.А. Чибиров}

Научное наследие Б.А. Калоева трудно назвать неизученным, но исследователи его творчества пока не уделили должного внимания трудам ученого, выполненным на фольклорном материале, на стыке этнологии и фольклористики. Изучение научного наследия Калоева позволяет ставить вопрос о весомом вкладе ученого не только в этнографическое кавказоведение, но и в фольклористику, в частности, в нартоведение. В настоящей статье впервые предпринята попьтка систематизации нартоведческих трудов Калоева, основанная на следующей схеме: публикации, посвященные нартовскому эпосу; этнограбические труды с широким привлечением текстов нартовских сказаний; словарные статьи в энииклопедических изданиях; научное редактирование и комментирование нартоведческих трудов. Такая систематизачия научных публикаций позволяет максимально привлечь имеющийся материал и всесторонне исследовать нартоведческие изыскания ученого. Калоев не ограничивался анализом текстов осетинских нартовских сказаний, проводил их сопоставление с текстами других национальных версий Нартиады и пришел $\kappa$ выводу, что осетинский нартовский эпос отличается более стройной единой композииией, наличием щелого ряда интереснейших ииклов, отсутствующих в других национальных версиях. Калоев солидарен с учеными, считающими VIII-VII вв. до н.э. начальным этапом формирования эпоса, и разделяет мнение исследователей эпоса, которые возводят создание его основного ядра к аланской эпохе. Ученый доказывает отражение нескольких эпох в нартовских сказаниях, в том числе монгольской и считает, ито некоторые сказания складывались в те времена, когда предки осетин были расселены вдали от современных грании, Осетии. Калоев рассматривает и анализирует эпос с этнографической точки зрения, находит массу параллелей из области культуры и быта осетинского и нартовского общества. Выявленные сходства подтверждают репрезентативность фольклорно-этнографического материала в этногенетических исследованиях. Калоев существенно обогатил научное нартоведение, внес вклад в фольклористику и в этнограбию осетин, в частности в проблему скифо-алано-осетинской преемственности.

Ключевые слова: Этнография, нартовские сказания, этнографические параллели, материальная и духовная культура, этногенез осетин, версии Нартиады.

The scientific heritage of B.A. Kaloev can hardly be regarded as not known, yet researchers of his creativity have paid insufficient attention to the investigations of the folklore material, conducted by the scientist at the intersection of Ethnology and folklore studies. The study of the heritage of Kaloev allows to raise the question about the significant contribution of the scientist, not only into the Caucasian, but also into ethnographic study of folklore, particularly in Nartology. In this article the first attempt is undertaken to systematize the Narts' studies of Kaloev, based on the following pattern: Narts' epic publications; ethnographic works with broad involvement of Narts' sagas, legends; lexicographic articles in encyclopedic publications; scientific editing and commenting Narts' studies. This systematization of scientific publications allows access to the available material and fully explore Narts' research of the scientist. Kaloev was not limited to the analysis of the texts of Ossetian Narts' sagas, but compared them with the texts of other national versions of Nartiada and came to the conclusion that Ossetian Narts' epos is distinguished by the unity of composition, the presence of a number of interesting cycles that do not exist in other national versions. Kaloev agrees with those scholars, who consider VIII-VII centuries BC being the initial stage of the epic formation, and shares the opinion of the researchers of the epic, who traced its nucleus to the Alanian era. The scientist proves that several eras are reflected in Narts' legends, including the Mongolian period and believes that some legends were formed at the time when the ancestors of the Ossetians 
were settled far from the modern borders of Ossetia. Kaloev reviews and analyses the epic from the ethnographic point of view, finds a lot of parallels in the areas of cultural and social life of Ossetian and Narts' society. Revealed similarities confirm the representativeness of the folklore-ethnographic material in an ethnogenetic research. Kaloev has significantly enriched the scientific Narts' studies, contributed to folklore studies and to the ethnography of the Ossetians, in particular to the problem of the Scythian-Alanian-Ossetian continuity.

Keywords: Ethnography, Narts' legends, ethnographic parallels, material and spiritual culture, ethnogenesis of Ossetians, Nartiada's versions.

Выдающийся российский ученый Б.А. Калоев своими многочисленными трудами вошел в историю науки как патриарх этнографического кавказоведения. Основная часть его исследований посвящена этнографии осетинского народа. Его фундаментальное исследование «Осетины» выдержало три издания [1]. В списке работ ученого немало трудов, посвященных этнографии других народов Кавказа, общекавказским проблемам.

Научное наследие Калоева трудно назвать неизученным, но исследователи его творчества пока не уделили должного внимания трудам ученого, выполненным на фольклорном материале, на стыке этнологии и фольклористики. Между тем, работы по нартовскому эпосу занимают столь видное место в научном наследии Калоева, что на полном основании его можно назвать и ученым-нартоведом. Не ограничиваясь осетинскими нартовскими сказаниями, Калоев не оставлял без внимания и другие версии Нартиады.

В своих нартоведческих изысканиях Калоев опирался на основополагающие установки В.Ф. Миллера, который обнаружил в осетинских нартовских сказаниях (как и в быту осетин) отголоски мифологии и культуры скифов, сарматов и алан.

Калоев много лет собирал полевой этнографический материал в осетинских ущельях, сопоставление которого с текстами нартовских сказаний подтвердило скифо-осетинские этнокультурные параллели, преемственность культуры осетин от скифо-сарматов и алан, значи- мость иранского элемента в этногенезе осетин [2,53].

Нартоведческие труды Калоева можно систематизировать следующим образом: научные статьи, специально посвященные нартовскому эпосу; этнографические труды с широким привлечением текстов нартовских сказаний; словарные статьи в энциклопедических изданиях; научное редактирование и комментирование нартоведческих трудов; Калоев неоднократно выступал в качестве составителя, автора комментарий и словников в ряде изданий осетинских нартовских сказаний.

Специальных статей по нартоведению у Калоева три; две из них написаны на основе научных докладов на форумах нартоведов во Владикавказе и Сухуме.

Наиболее значимой нам представляется статья «Некоторые этнографические параллели к осетинскому нартскому эпосу» [3]. Она представляет собой переработанный вариант доклада ученого на сухумском совещании нартоведов в 1968 г., где Борис Александрович рассматривает и анализирует эпос с этнографической точки зрения, проводит массу параллелей из области культуры и быта осетинского и нартовского обществ. Выявленные сходства показывают репрезентативность фольклорно-этнографического материала в этногенетических исследованиях. Доклад оставляет солидное впечатление своей аргументированностью и завершенностью и подтверждает сложившееся представление о нартовском эпосе как художественной автобиогра- 
фия осетинского народа. Выявленными аналогиями ученый констатирует: значительная часть элементов материальной и духовной культуры осетинского народа нашла отражение в нартовском эпосе. В действительности, читатель нартовских сказаний, знакомый с особенностями культуры народа, непременно обнаружит сходство с осетинским селением второй половины XIX в.: те же родовые поселения, те же жилища (хадзар), те же башни, склепы, культура застолья с почетным бокалом, осетинский треножный стол, хмельные напитки, та же одежда, те же божества (Реком, Мыкалгабыр, Таранджелоз, Сафа, Курдалагон), те же представления о загробной жизни, поминальная культура и т.д. Яркие параллели в материальной культуре осетин и в сказаниях о нартах автор выявляет буквально во всех элементах материальной и духовной культуры осетин. «В сказаниях о нартах, -констатирует Калоев, - нашли отражение почти все виды занятий обитателей предгорья Центрального Кавказа: охота, рыболовство, скотоводство, ремесла, земледелие» [3, 128].

Нартовские сказания сохранили описание территории расселения алан-осетин. «Об этом, свидетельствует, - пишет Калоев, - постоянное упоминание в эпосе рек и морей, в том числе Черного моря. Известно, что современная Осетия не имеет больших рек и находится далеко от морей. Тем не менее, в осетинской мифологии значительную роль играют такие божества, как владыка морей Донбеттыр (в честь которого осетины-горцы ежегодно устраивали праздник) и властелин рек Гатаг, занесенные на Центральный Кавказ, вероятно, предками осетин из прежних мест их обитания» $[3,125]$. О прежнем месте расселения предков осетин свидетельствует упоминание в эпосе повелителя рыб - Хуандон-алдаре, в котором Абаев видел владетеля Боспорского пролива. Анализ сюжетов осетинских нартовских сказаний позволил ученому сделать вывод: в эпоху средневековья аланы-осетины жили в центральной части Северного Кавказа, где они близко соседствовали с адыгами, абхазами, с горцами Грузии и Дагестана, вайнахами. В целом, приведенные Калоевым многочисленные этнографические параллели к нартовским сказаниям свидетельствуют о большом сходстве материала, выявленного в сказаниях о нартах и в осетинском быту.

Статья Калоева «Мотив амазонок в осетинском нартовском эпосе» вышла в Кратких сообщениях Института этнографии АН СССР [4]. Как известно, греческие предания связывают появление амазонок с Северным Причерноморьем и при этом не столько со скифами, сколько с родственными им савроматами. Большое внимание амазонкам уделили Геродот и другие античные авторы. При этом, все они представляют их воинственными женщинами.

Автор рассматриваемой статьи находит схожие явления в греческих легендах и нартовских сказаниях, проводит параллели с эпосами народов Средней Азии и Казахстана, вводит в научный оборот соответствующие сюжеты осетинской Нартиады (Дочь Даргавсара, Сатана-Сатаник и др.) [4,115-119]. На основе анализа большого количества фольклорных и литературных источников Калоев приходит к выводу о том, что древнее население, представленное в нартовских сказаниях, ведет свое начало из Средней Азии, откуда двигались на юг России ираноязычные племена. Вопрос о среднеазиатской прародине скифов, сармат и аланов ученый обоснованно и аргументировано исследовал в статье «Этнографические данные о связях этногенеза осетин со Средней Азией» [11].

Как указано выше, вторая группа нартоведческих трудов Калоева представлена этнографическими исследованиями 
с широким привлечением нартовских сказаний. Прежде всего, здесь следует указать фундаментальный труд «Осетины». Монография переиздавалась три раза $(1967,1976,2004)$ и с каждым разом ее объем значительно расширялся, в том числе и фольклорный.

В монографии кратко обозревается история записи сказаний, публикации текстов, выявляется вклад представителей первого поколения осетинской интеллигенции, в частности, братьев Шанаевых, в собирание и публикацию сказаний. Большое внимание уделено предпринятой В.Ф. Миллером научной интерпретации некоторых сюжетов сказаний о нартах.

Сравнивая отдельные версии Нартиады, Калоев заключает, что осетинский нартовский эпос отличается «более стройной единой композицией, наличием целого ряда интереснейших циклов, например цикла о Сырдоне, отсутствующего в других национальных версиях» $[1,418]$. Он солидарен с учеными, считающими VIII-VII вв. до н.э. начальным этапом формирования эпоса, и разделяет мнение исследователей эпоса, которые возводят создание его основного ядра к аланской эпохе. Ученый пишет об отражении нескольких эпох в нартовских сказаниях, в том числе монгольской. Как правильно считает Калоев, некоторые сказания складывались, когда предки осетин находились вдали от современных границ Осетии.

Калоев своими этнофольклорными исследованиями убедительно свидетельствовал о восточном происхождении прародины иранских племен.

Заслуживает также внимания доклад Калоева «Данные этнографии и фольклора о происхождении осетин», представленный на важном научном форумевсесоюзной сессии по этногенезу осетин осенью 1966 года [5]. Для доказательства основной идеи докладчик, наряду с этно- графическими сведениями, ввел в научный оборот археологические материалы и эпические сказания осетин.

Приведем несколько иллюстраций к сказанному. Археологические артефакты свидетельствуют о наличии развитого рыболовства в местах обитания скифо-сармато-аланских племен (бассейны рек Кубань, Дон, Терек, особенно Керченский пролив, где находились крупные рыбные промыслы Боспорского царства). К этим материалам докладчик проводит следующую параллель из эпоса. Нарт Сослан, во время своего путешествия в загробный мир, встретил на берегу большой реки трех братьев - великанов, занимавшихся рыбной ловлей. При этом удилищем для одного из них было огромное дерево, а вместе червяка-крупное животное $[5,100]$.

Известна значимая роль боевого коня в быту скифо-сармато-аланских племен. Превосходные качества такого коня-воина Калоев увидел в образе знаменитого Арфана - коня старейшего из нартов, Урузмага. Развивая эту тему, ученый доказывает, что не только аланы, но и осетины с детства приобщались к верховой езде, считали позором ходить пешком. Ученый отмечает преемственность этой традиции, указывая на большое число известных наездников среди осетин, в частности всемирно известных осетинских джигитов Алимбека Кантемирова.

Следующая убедительная параллель связана с занятием пчеловодством. Оно было так сильно развито у алан, что, как пишет проф. Робакидзе, некоторые формы славянского улья проникли в Грузию через аланское посредство. Борис Александрович приводит убедительные иллюстрации о важном месте пчеловодства в нартовском эпосе: из меда пекли пироги, которыми, как правило, Сатана молилась богам; из меда нарты изготовляли любимый напиток ронг, и все это свидетельство того, что культура пчеловодства у 
осетин - очень древняя [5, 104-105]. Отражение материальной культуры осетин в нартовском эпосе Калоев иллюстрирует и на примерах жилых и крепостных сооружений, пивоварения, ремесел, гончарного дела и др.

Таким образом, основной тезис доклада - участие древнекавказского и скифо-сармато-аланского пласта в этногенезе осетин, Калоев подтвердил фольклорно-этнографическим материалом, особенно нартовским эпосом осетин.

Не проходит мимо нартовских сказаний Калоев и в статье «Скифо-сармато-аланские параллели» [2]. Вновь о традициях рыболовства и его отражении в осетинской Нартиаде. Также автор статьи проводит параллель между обычаем скифов посвящать покойнику «самых красивых коней» (Геродот) и нартовскими сказаниями, где обозначено несколько типов лошадей, среди которых - треногий конь (жефсург) мигом спускающийся на землю и также поднимающийся в небеса. Ученый заостряет внимание на известную роль волка-собаки в скифо-сармато-аланском обществе, сопоставляет ее с нартовской знаменитой собакой Сырдона, и с не менее популярной собакой Силам; последнюю эпос считает родоначальницей всех собак [2,42-44].

Серия статей Калоева по нартовским сказаниям осетин была опубликована в различных академических и энциклопедических изданиях. Так, в первый том «Народов Кавказа» (серия «Народы мира» Института этнографии АН СССР, Москва 1961) включен очерк Калоева об осетинах, содержащий материалы и о фольклоре. Борису Александровичу не раз поручалось составление статей и по мифологии осетин для солидных академических изданий, например, «Мифы народов мира» [6]. В этих солидных изданиях содержатся десятки статей разного объема и информативности, в которых широко представлены нартовские сказа- ния со всеми характерными особенностями (сюжет, циклы, главнейшие герои и т.д.). Из статей, написанных Калоевым для этой энциклопедии, наиболее значимая по объему и содержанию - «Oceтинская мифология». Калоев не обошел стороной нартовские сказания и в обобщающей статье «Осетины» для другого энциклопедического издания - «Народы России» [7].

Как признанный специалист, Калоев привлекался к сотрудничеству при очередных изданиях осетинских нартовских сказаний. Еще в 1951 г. вышли нартовские сказания в Москве. Калоев, вместе с В.И. Абаевым, Н.Г. Джусойты и Р.А. Ивневым был в числе составителей и тех, кто снабдил издание комментариями и послесловием. Словарь и комментариии Калоев подготовил и к книгам «Сказания о нартских богатырях» (М., 1960), «Сказания о нартах. Осетинский эпос» (М., 1978).

Как было отмечено выше, наряду с исследованием осетинских версий нартовских сказаний, Калоев внес определенный вклад в изучении Нартиады в целом, отдельных ее версии.

В 1956 г. он выступил с докладом «История записи и публикации нартского эпоса» на Орджоникидзевском (Владикавказском) совещании по нартовскому эпосу. В виде статьи доклад вошел в сборник «Нартский эпос» с приложением к ней библиографии, которая состоит: из опубликованных текстов нартовского эпоса (осетинский, кабардино-адыгский, карачаево-балкарский, чечено-ингушский), перечня исследований по эпосу и библиографической справки о некоторых собирателях и исследователях нартовского эпоса [8].

В таком обобщающем ракурсе начальный этап записи и публикации был представлен впервые. Вслед за Калоевым, историю сбора и публикации нартовских сказаний кавказских народов 
описал Ю.С. Гаглойти в книге «Некоторые вопросы историографии нартского эпоса».

Калоев делит историю изучения эпоса на три периода: первая половина XIX в.; 60-е гг. XIX в. - 1917 г.; советский период. В хронологической последовательности им рассмотрена каждая из версий. В статье много интересного о сказителях эпоса, о первых собирателях среди всех народов Северного Кавказа и Абхазии. Автор правильно подметил, что наиболее тщательно эпос разрабатывался у осетин и кабардинцев, и выразил пожелание ускорить работу по сбору сказаний у других кавказских народов - носителей эпоса $[8,110-128]$. Он же прокомментировал итоги совещания нартоведов на страницах журнала «Советская этнография» [9].

Вопросы эпоса довольно ярко представлены и в статье Калоева «Осетино-вайнахские этнокультурные связи». В заключительной части статьи он останавливается на нартовских сказаниях вайнахов, проводит параллели с осетинскими версиями. Ученый правильно считал, что ингушские сказания наиболее близки к осетинским. Что касается чеченских, то они потеряли многие исконные черты, особенно это заметно среди чеченцев, переселившихся на равнину. Ингушские же ближе к осетинским не только по сюжету, но и по именам героев. Дальше на восток с Чечней соседствует Дагестан, где нартовские сказание не были известны вовсе. Следовательно, распространение этого фольклорного памятника проходило в данном случае с запада на восток [10, 105].

Соглашаясь в принципе с В. Миллером в том, что эпос формировался в степях Северного Кавказа, Б. Калоев настоятельно указывает на горную природу нартовской территории, на события про- исходящие в горах, на жизнь великанов в пещерах. Калоев ссылается на первого собирателя ингушской версии эпоса Чаха Ахриева, и указывает на соседство ингушского народа с Осетией, а именно с тагаурским селением Саниба. Как пишет Калоев, ингушские (орстхойские) сказания и сказания о великанах-циклопах, распространенные повсеместно в Чечне и Ингушетии, весьма сходны с осетинскими нартовскими сказаниями $[10,105]$. Эти мысли автор статьи иллюстрирует именами ингушских и осетинских нартов: Соска-Солса-Сослан (Сырдон), Орзма-Урузмаг, Патраз-Батрадз, Ширтка-Сырдон и др. Сходство осетинских и вайнахских эпических сказаний проявляется во многом; в них фигурируют великаны-людоеды, циклопы. Сходства обнаружены и в традиционной системе наказаний [10, 105-106].

Калоев ограничился констатацией близкого сходства нартовских сказаний осетин и вайнахов и не проанализировал его причины. Между тем, для нас очевидно, что из множества ингушских обществ, нартовские сказания получают распространение только в обществе примыкающем к Восточной Осетии (Caниба). Кроме того, о многом говорит ослабление распространенности сказаний по мере удаленности от Осетии на восток (чеченцам они меньше известны, чем ингушам, а у дагестанцев их вовсе нет). Все эти факты указывают, что на территорию Ингушетии сказания могли проникнуть только из Восточной Осетии, от осетин Тагаурского ущелья, о чем свидетельствовал и сам Ч. Ахриев.

Подводя итоги, отметим, что своими трудами по исследованию нартовского эпоса, Б.А. Калоев обогатил научное нартоведение, а также внес существенный вклад в исследование этногенеза и этнической культуры осетин. 
1. Калоев Б.А. Осетины. Историко-этнографическое исследование. Изд. 3-е. М., 2004.

2. Калоев Б.А. Скифо-сармато-алано-осетинские параллели // Осетинские историко-этнографические этюды. М., 1999.

3. Калоев Б.А. Некоторые этнографические параллели к осетинскому нартскому эпосу // Сказания о нартах - эпос народов Кавказа. М., 1969.

4. Калоев Б.А. Мотив амазонок в осетинском нартском эпосе // Осетинские историко-этнографические этюды. М., 1999.

5. Калоев Б.А. Данные этнографии и фольклора о происхождении осетин // Происхождение осетинского народа, Орджоникидзе, 1966.

6. Мифы народов мира. М., 1991.

7. Народы России. М., 1994.

8. Калоев Б.А. История записи и публикации нартского эпоса // Нартский эпос. Орджоникидзе, 1957.

9. Калоев Б.А. Совещание по нартовскому эпосу народов Кавказа // Советская этнография. 1957. № 3. С. 171-174.

10. Калоев Б.А. Осетино-вайнахские этнокультурные связи // Осетинские историко-этнографические этюды. М., 1999.

11. Калоев Б.А. Этнографические данные о связях этногенеза осетин со Средней Азией // Вопросы общей и иранской филологии, Тбилиси, 1977. 